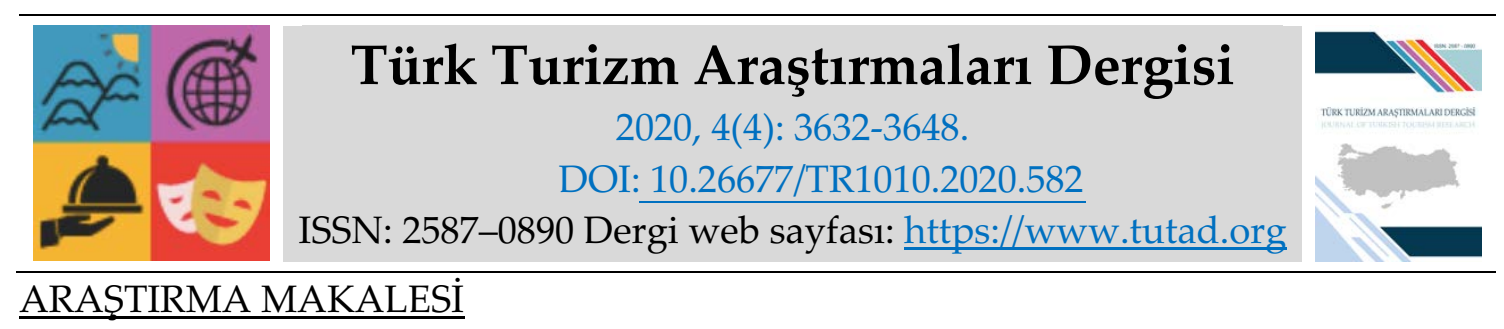

\title{
Turistik Seyahatlerde Unutulmaz Yemek Deneyiminin Davranışsal Niyete Etkisi: Gaziantep Örneği
}

Dr. Öğr. Üyesi Emrah KESKİN, Hacı Bektaş Veli Üniversitesi, Turizm Fakültesi, Nevşehir, eposta: ekeskin@nevsehir.edu.tr

ORCID: https://orcid.org/0000-0001-6565-4265

Nevres SEZEN, Yüksek Lisans Öğrencisi, Hacı Bektaş Veli Üniversitesi, Sosyal Bilimler Enstitüsü, Nevşehir, e-posta: nevressezen67@gmail.com

ORCID: https://orcid.org/0000-0002-0198-5441

Tuğba DAĞ, Yüksek Lisans Öğrencisi, Hacı Bektaş Veli Üniversitesi, Sosyal Bilimler Enstitüsü, Nevşehir, e-posta: tugba.dag.01@gmail.com

ORCID: https://orcid.org/0000-0003-4571-4499

Öz

Zengin bir kültüre ve tarihi geçmişe sahip olan Gaziantep, sahip olduğu mutfak kültürü ve yemekleriyle Türkiye'nin en önemli gastronomi şehirlerinden birisidir ve çok sayıda turist tarafından ziyaret edilmektedir. Bu nedenle Gaziantep'i ziyaret eden yerli turistlerin unutulmaz yemek deneyimlerinin belirlenmesi ve bu deneyimlerinin davranışsal niyetlerine etkisinin tespit edilmesi önemli görülmektedir. Bu amaç doğrultusunda 4 hipotez geliştirilmiştir. Hipotezleri test etmek için nicel araştırma yöntemi kullanılmış ve veriler anket tekniğiyle elde edilmiştir. Anketler, tesadüfi örnekleme yöntemlerinden birisi olan basit kümeleme örneklem tekniğiyle Mayıs-Haziran 2020 aralığında, bölgeyi ziyaret etmiş turistlere e-anket uygulanarak toplanmıştır. Yapılan analiz sonuçları incelendiğinde unutulmaz yemek deneyiminin boyutları ile davranışsal niyet arasında pozitif yönlü ilişki olduğu tespit edilmiştir. Ayrıca unutulmaz yemek deneyiminin boyutlarından olan seçkin ve leziz yemekler ve yüksek değer algısı ile davranışsal niyet arasında pozitif yönlü ve anlamlı bir ilişkinin olduğu tespit edilmiştir.

Anahtar Kelimeler: Unutulmaz Yemek Deneyimi, Davranışsal Niyet, Gastronomi Turizmi, Memnuniyet, Gaziantep.

Makale Gönderme Tarihi: 10.06 .2020

Makale Kabul Tarihi: 03.10.2020

\section{Önerilen Atıf:}

Keskin, E., Sezen, N. ve Dağ, T. (2020). Turistik Seyahatlerde Unutulmaz Yemek Deneyiminin Davranışsal Niyete Etkisi: Gaziantep Örneği, Türk Turizm Araştırmaları Dergisi, 4(4): 3632-3648.

(c) 2020 Türk Turizm Araştırmaları Dergisi. 


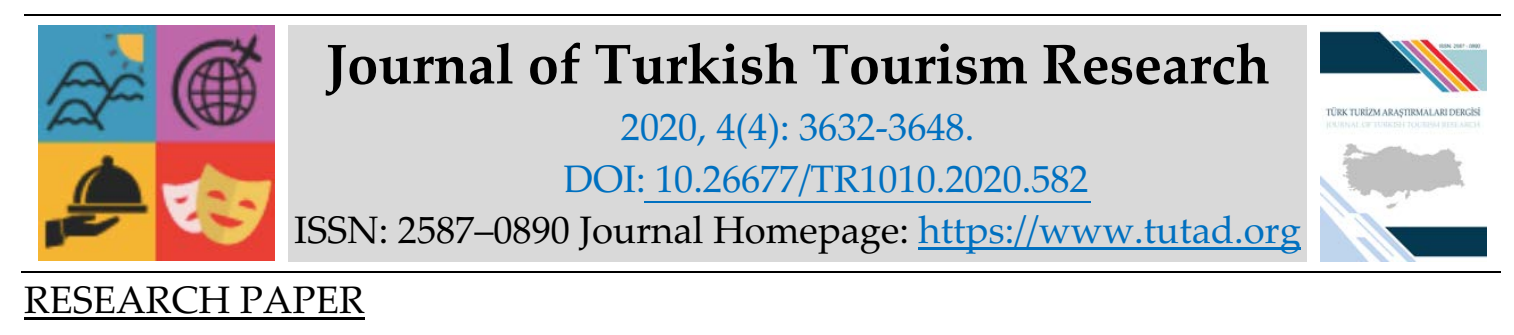

\title{
The Effect of Memorable Food Experience on Behavioral Intention in Touristic Travel: Sample of Gaziantep
}

Assistant Prof. Dr. Emrah KESKIN, Hacı Bektaş Veli University, Faculty of Tourism, Nevşehir, email: ekeskin@nevsehir.edu.tr ORCID: https://orcid.org/0000-0001-6565-4265

Nevres SEZEN, MSc. Student, Hacı Bektaş Veli University, Social Sciences Institute, Nevşehir, email: nevressezen67@gmail.com ORCID: https://orcid.org/0000-0002-0198-5441

Tuğba DAĞ, MSc. Student, Hacı Bektaş Veli University, Social Sciences Institute, Nevşehir, email: tugba.dag.01@gmail.com

ORCID: https://orcid.org/0000-0003-4571-4499

\begin{abstract}
Gaziantep, which has a rich cultural and historical background, is one of the most important gastronomic cities in Turkey with its culinary culture and food and is visited by a large number of tourists. Therefore, it is important to determine the memorable food experiences of local tourists visiting Gaziantep and the effects of these experiences on their behavioral intentions. Four hypotheses have been developed for this aim. Quantitative research method was used to test hypotheses and data was obtained by survey technique. Data was collected from the tourists who visited the region between May-June 2020 with e-surveys by using simple clustering sampling technique, which is one of the random sampling methods. When the results of the analysis are examined, it is shown that there is a positive correlation between the dimensions of the memorable dining experience and behavioral intent. It is also found that there is a positive directional and meaningful relationship between the perception of higher value and behavioral intent and the outstanding and delicious dishes that are the dimensions of a memorable dining experience.

Keywords: Memorable Food Experience, Behavioral Intention, Gastronomy Tourism, Satisfaction, Gaziantep.

Received: 10.06 .2020

Accepted: 03.10.2020

Suggested Citation:

Keskin, E., Sezen, N. and Dağ, T. (2020). The Effect of Memorable Food Experience on Behavioral Intention in Touristic Travel: Sample of Gaziantep, Journal of Turkish Tourism Research, 4(4): 36323648.
\end{abstract}

(C) 2020 Türk Turizm Araştırmaları Dergisi. 


\section{Gíriş}

Dışarıda yemek yeme, evrensel bir davranış olup, yaş, sınıf, coğrafya ve kültürlere göre farklılıklar göstermektedir (Smith, 1983). Yeme-içmenin önemli bir yere sahip olduğu günümüzde, seyahat esnasında dışarıda yemek yeme davranışları mutlaka gerçekleştirilmektedir. Seyahat sürecinde beslenme ihtiyacı karşılanırken, hoş ortamlarda, çeşitli yiyecekler deneyimlenerek seyahatten zevk alma ihtiyacı giderilmektedir (Pillsbury, 1990; Reynolds, 1994; Hjalager ve Corigliano, 2000). Yiyecek ve içecekler, turistler için önemli bir motivasyon unsuru olması nedeniyle, gastronomi amaçlı seyahat yapma isteğinde, destinasyon seçiminde ve deneyimlerin değerlendirilme aşamasında güçlü bir etkiye sahiptir (LopezGuizman vd., 2017; Solunoğlu, 2019; 479).

Destinasyonlar, turistlerin seyahat esnasında çeşitli yiyecek seçimleri yapmaktan kaçınmadıkları, özellikle de tanımadıkları yiyecekleri tüketmeyi tercih ettikleri alanlardır. Turistler restoranlarda deneyimleyecekleri yiyecekleri istekleri doğrultusunda memnun kalmayı arzulayarak seçmektedir. Çeşitli yiyecekler konusunda olumlu deneyimler yaşanmış ise seyahatten memnun ayrılma söz konusu olmaktadır. Bu nedenle yiyecekler, bir destinasyonun önemli çekicilik unsurlarındandır (Richards, 2002; Cohen ve Avieli, 2004). Doğal, kültürel ve sosyal unsurlar bir destinasyonun benzersiz deneyim faktörlerini oluşturmaktadır (Yayla ve Yaylı, 2019). Kültürel değerler içerisinde yer alan gastronomik unsurlarda deneyim yaşanmasında önemlidir. Bu nedenle gastronomik unsurlardan olan yerel yemekler bir bölgenin hem genel kültürünü hem de yiyecek-içecek kültürünü tanıtması açısından önemlidir. Bir bölgenin sahip olduğu gastronomik değerler o bölgeyi ziyaret eden turistler için önemli bir cazibe unsurudur ve bölgenin tekrar ziyaret edilmesinde etkilidir (Ignatov ve Smith, 2006; Henderson, 2009; Björk ve KauppinenRaisanen, 2014; Kumar, 2019).

Gastronomik deneyimler, turizmde yerel mutfakların arandığı ve deneyimlendiği faaliyetlerden olduğu için, yerel mutfaklarda yapılan yiyecek deneyimleri, turistler için önemli bir motivasyon unsurudur (Su, 2013). Yerel yiyecek deneyimleri ile turistlere hem mutfak bilgisi sağlanmakta hem de yeni yiyecek arayışlarına girmeleri teşvik edilmektedir (Ellis vd., 2018). Cruz ve arkadaşları (2019) yaptıkları bir çalışmada gastronomi turistlerinin yerel mutfaklara yönelik olan ilgilerini kültürel deneyim, heyecan, kişilerarası ilişki, duygusal çekicilikler ve sağlık olmak üzere beş boyut altında incelemiştir. Bu çalışmaya göre kültürel deneyim, sağlık endişesinin olmaması ve duygusal çekicilik unsurları gastronomi turistlerinin yerel mutfak deneyimlerinden memnun olmalarını sağlamaktadır.

Seyahat edilen destinasyonda turistlere olumlu deneyimler yaşatmak, turizm endüstrilerinin müşterileri memnun etmek için yapması gerekli uygulamalardandır (Keskin, Sezen ve Dağ, 2020; Ritchie vd., 2011). Destinasyonlarda gastronomik zenginliğin gösterilmesini sağlayan doğal ve sağlıklı yerel yiyecekler, turistlere eşsiz ve unutulmaz deneyimler yaşatılmasına sağladığı katkı ile deneyimlerde memnuniyet davranışları gösterilmesini sağlamakta ve deneyimlere olumlu etkilerde bulunmaktadır (Haveng-Tang ve Jones, 2005). Bu nedenle gastronomi turizmine yönelmiş destinasyonların misafirlere unutulmaz yemek deneyimleri yaşatmaları gerekli görülmektedir.

Türkiye'nin gastronomi turizminde Gaziantep önemli bir yere sahiptir. Gaziantep'in zengin yerel yemek kültürü ve bu kültürün ülke genelinde tanınıyor olması, başka yerlerde de Gaziantep yerel yemeklerinin yapılması insanların Gaziantep yemek kültürü hakkında bilinçli olmasına katkı sağlamıştır. Bu nedenle yerel yemekler Gaziantep iline yapılan seyahatlerde etkili olan önemli bir faktördür. Şengül (2017)' ün yaptı̆̆ çalışmada gastronomi turizmine yönelik seyahatlerde Gaziantep Türkiye'nin en fazla ziyaret edilen ili olarak tespit edilmiştir. Elde edilen bu bulgu turistlerin bu bölgeyi yeme-içme motivasyonuna bağlı olarak ziyaret ettiklerini ortaya 
koymaktadır. Bu nedenle Türkiye'nin önemli bir gastronomi merkezi olan Gaziantep'i ziyaret eden yerli turistlerin unutulmaz yemek deneyimlerinin belirlenmesi ve bu deneyimlerinin davranışsal niyetlerine etkisinin tespit edilmesi önemli görülmektedir.

\section{LITERATÜR}

\section{Yemek Deneyimi}

Unutulmaz turizm deneyimleri, turistik faaliyetler gerçekleştirildikten sonra olumlu olarak hatırda kalan deneyimlerdir (Kim vd., 2012). Turizm deneyimlerinde aktivitelerin yoğunluğu oldukça fazladır (Yaylı ve Çetiner, 2020). Yemek de turistik faaliyetlerde unutulmaz deneyimler yaşanmasında etkili olan olağanüstü bir aktivite unsurudur (Chang, 2011). Pek çok turist yemek keşifleri için dünyanın herhangi bir yerine seyahatler yapmakta ve bir bölgenin yerel kültür miraslarından biri olan gastronomi mirasını tanımakta ve onu deneyimlemektedir (Gordin ve Trabsikaya, 2013).

Yemek turizmi, gastronomi turizmi, mutfak turizmi ya da gurme turizmi olarak da bilinir. Bu turizm türünde amaç yiyecek aramak ve deneyimlemektir (Ellis vd., 2018). Kivela ve Crotts (2009)'a göre yiyecekler seyahatlerin ayrılmaz bir parçasıdır. Bu nedenle unutulmaz turizm deneyimleri içerisinde yiyecek deneyimleri önemli bir etkiye sahiptir. Ayrıca yiyecekler, deneyimleri unutulmaz kılan en etkili çekilik faktörlerindendir. Turistler, yiyecek ve içecekler vasıtasıyla unutulmaz deneyimler yaşama imkânı bulurlar. Yemeklerin cazibesi, festivaller ve yerel yiyecek tanıtımlarının yapıldığı diğer aktiviteler unutulmaz deneyimlerin yaşanmasına etki eder (Chen ve Huang, 2018). Yemek turizminde, turistler için cazibe unsuru bir deneyim olan yerel yiyecekler turistik deneyimlerin önemli bir kısmını oluşturmakta, aynı zamanda turistlerin seyahatlerini nerede ve nasıl gerçekleştireceklerine de etki etmektedir (Richards, 2002). Mitchell ve Hall (2003)' a göre yerel yiyecekler, destinasyona gelen farklı kültürlerden misafirlerin yemek deneyimi yapmaları için önemlidir. Turizm ürünleri, yemek servisi, hizmet, ulaşım, kamu hizmeti, yerel halkın turizme ve turistlere tutum ve desteği turistik deneyimlerin kalitesini etkilemektedir. $\mathrm{Bu}$ nedenle destinasyonların sahip olduğu yemek kültürleri unutulmaz deneyimde önemlidir.

Pine ve Golmore (1999)'a göre deneyimler insanlarda duygusal, fiziksel ve entelektüel etkiler bıraktığı için manevi olarak unutulmaz olmaktadır. Turistik deneyimlerin başlangıcından sonuna kadar tüm iç ve dış faktörler deneyimin algılanmasında etkili olmaktadır. Yemek deneyimleri deneyim öncesi, deneyim anı ve deneyim sonrası olmak üzere üç aşamada gerçekleşmektedir. İnsanların deneyim öncesindeki beklentileri, deneyim esnasında yemeğin tüketildiği ortamı oluşturan somut ve soyut unsurlarla etkileşimleri ve deneyimden sonraki aşamada oluşan memnuniyetleri veya memnuniyetsizlikleri, onların bir sonraki deneyim davranışlarında etkili olabilmektedir. Bu nedenle iyi mutfak kültürüne sahip olan destinasyonlar, turistlerin seyahatlerinden hoş yemek deneyimleri yaşayarak ayrılmalarına olanak sağlayabilmektedir. (Wijaya vd., 2013).

Turizm seyahati esnasında turistlerin yiyecek deneyimleri yapmalarında bireylerin kültürel özellikleri, yiyeceklerle ilişkisi, geçmişteki yemek deneyimleri ve motivasyon faktörleri etkili olmaktadır. Ayrıca deneyimlenmesi düşünülen yiyeceklerin duyusal özellikleri, içeriği, hazırlama ve pişirme yöntemleri, yiyeceklerin türü, bulunabilirliği ve fiyatı da etkilidir (Mak vd., 2012; Wijaya vd., 2013).

Restoranlar yerel yiyecek deneyimleri için tercih edilen mekânlar içerisindedir. Restoranların müşterilere yiyeceklerinin otantikliği hakkında bilgiler sunması ve otantik yemek deneyimi ortamını oluşturan unsurlar hakkında bilgilendirme yapması misafirlerinin unutulmaz 
deneyimler gerçekleştirmesine imkân sağlamaktadır. Otantikliğin ana kaynakları hakkında bilgisi olan misafirlerin yiyecek-içecek işletmesine olan güveni ve memnuniyeti artmaktadır. Bu nedenle restorana güven duyan, kendini memnun hisseden ve unutulmaz deneyimler yaşayan misafirler aynı restoranı tekrar ziyaret etme niyeti içerisine girmektedir (Gilmnore ve Pine, 2007; Chhabra vd., 2013; Keskin, Solunoğlu ve Aktaş, 2020).

Quan ve Wang (2004)' a göre yemek deneyimlerinde merkezi ve çevresel roller bulunmaktadır. Toplumların kimlik arayışına girmesi ile turistlerin gastronomi deneyimleri oluşmaya başlamıştır. Bu nedenle deneyimler için seyahatler yapılmaktadır. Unutulmaz yemek deneyimleri, seyahatlerde motivasyon ve memnuniyetin sağlanmasında güçlü etkisi olan faktörlerdendir (Ottenbacher ve Harrington, 2013). Turistik faaliyetlerde seyahatlerin asıl amac1 yiyecekler olmasa bile, yerel yiyecekler her zaman dikkat çeken ve turistleri memnun etmek için etkiye sahip kültürel unsur olmuştur. Ayrıca yerel yiyecekler destinasyonların kültürünü keşfetme isteğinde bir ön koşuldur (Long, 2006). Mykletun ve Gyimóthy (2010)'e göre geleneksel yemekler, destinasyonların orijinale bağlllıkta ne kadar kaliteli olduklarını göstermektedir. Bu nedenle turistler, yemek deneyimlerinde hem yerel kültüre bağlı olması hem de doğallığını korumasından dolayı yerel yiyeceklere önem vermektedir (Sims, 2009).

Huang (2017)' in yaptı̆̆ çalışmaya göre yemek deneyiminin değeri ve hizmetin algılanması yerli ve yabancı turistlere göre farklılıklar göstermektedir. Çalışmaya göre yabancı turistler yemek deneyimlerinde farklılıklara daha duyarlıdır. Bu nedenle yemek deneyimlerindeki çeşitli hizmetleri yerli turistlere göre daha olumlu algılamaktadırlar. Bu durum yabancı turistlerin yemek deneyimleri için farklılıklara daha açık olduklarını ve daha olumlu geri dönütler verdiklerini göstermektedir.

Yemeklerin tüketilmesinin ardından, bir sonraki yiyecek ve mekân seçimlerinde, yemek deneyimlerinden hatırda kalanlar doğrultusunda hareket edilmektedir. Yiyecek-içecek işletmelerinin misafirleri için yemeklerin nasıl yapıldığı ve deneyimden sonra nasıl hatırlanacağ önemlidir (Miao vd., 2013). Cao (2018)' ya göre unutulmaz turizm deneyimlerini oluşturan faktörler restoranlar tarafından bilinmeli ve restoranlar misafirlere unutulmaz deneyimler yaşatma doğrultusunda geliştirilmelidir. Çünkü bu deneyimler misafirlerin hatırlarında kalarak gelecekteki tüketim davranışlarını etkilemekte ve tekrar ziyaret niyetlerinin oluşmasını sağlamaktadır.

Yemek deneyimlerinde misafirler yemek deneyimleme aşamasındayken mekândaki diğer misafirleri gözlemleme, restoranda eğer varsa şovları izleme, şarkı söyleme, müzik gruplarını izleme ve dinleme gibi etkinliklerle deneyimlerini fiziksel ve zihinsel olarak gerçekleştirmiş olmaktadır. Restoranlarda yemek deneyimi esnasında sakin müziklerin yemeğe eşlik etmesi, mum ile aydınlatmalar yapılması, misafirlere kendilerini özel hissettiren hizmetler sunulması ve sunulan yemeklerin kaliteli olması unutulmaz deneyimlerde etkili olmaktadır. Restoranlarda kullanılan teknolojik unsurlar da unutulmaz deneyim yaşanmasında etkilidir. Misafirlerin sipariş verirken ve garsonlarla iletişim kurarken iPad kullanmaları olumlu algılanan deneyimler meydana getirmektedir. Misafirlere sosyal ağlarda restoran hakkında yorum yapmalarını önermek ve aynı restoranları deneyimleyenlerin iletişim kurmalarını sağlamak da deneyimler için etkili olabilmektedir (Jang ve Namkung, 2009; Cao vd., 2018).

\section{Davranışsal Niyet}

Davranışsal niyet, turistlerin kişisel normlarını kendi değer sistemlerine göre belirli davranışlarla çevreye yansıtmasıdır. Kişisel normlar, seyahat sürecinde bireylerin çevresine karşı göstermiş olduğu tutum ve davranışlar açısından önemlidir (Schwartz, 1977; De Groot ve Steg, 2009; 
Berenguer, 2010; Han vd., 2016). Planlı davranış teorisine göre insanların davranışsal niyetleri üç ön koşul ile oluşmaktadır. Bunlar davranışa karşı tutumlar, kişisel normlar ve algılanan davranışsal kontroldür. Planlı davranış teorisinin oluşturmuş olduğu ön koşullar doğrultusunda insanların davranışsal niyetleri ve davranışları tahmin edilebilmektedir (Ajzen, 1991; Liu vd., 2020).

Turistlerin turistik davranışları gerçekleştirme olanakları, bilgileri, yetenekleri, becerileri ve destinasyonun turistik kaynaklara sahip olduğuna dair inançları destinasyon ziyaretlerinde olumlu davranış niyetlerinin oluşmasını sağlamaktadır. (Brown vd., 2010). Ayrıca turistler deneyim yaşamayı düşündüğü destinasyonda davranışsal kontrole sahip olduklarını hissedebilirler. Bu his onların davranışsal kontrol sergileyebildikleri destinasyonlara olan ziyaret etme niyetlerini etkiler. Bundan dolayı bireylerin turizmde yaşamış oldukları olumlu deneyimler; olumlu davranışsal niyet, tekrar ziyaret ve tavsiye niyeti oluşmasında etkilidir $(\mathrm{Qu}$ vd., 2011; Chen ve Tung, 2014).

Bireyler davranışsal niyetlerini gerçekleştirirken veya gerçekleştirmeden önce başkalarının düşüncelerine önem vermektedirler. Başkalarının yaşamış olduğu deneyimlerin değerli olduğunu düşünen bireyler, aynı deneyimleri yaşayıp benzer davranışsal niyetler gösterebilmektedir. Destinasyonda deneyimlenen yiyeceklerin özgünlüğü turistik deneyimler için önem arz etmektedir. Özellikle özgün yemeklerin sosyal medyada paylaşımı ile turistlerin deneyim davranışlarında değişiklikler oluşmakta ve sosyal medyada özgünlüğü tanıtılan yiyecekler için talep oluşabilmektedir (Ajzen, 1991; Song vd., 2014; Le vd., 2019).

Yuan (2009)'ın turistik deneyimlerdeki davranış ve tutumları incelediği çalışmasında, deneyimlerde fiziksel unsurlar, hizmet ve çevre turistlerin deneyimi algılamalarında, katılımlarında ve etkileşimlerinde etkili olmaktadır. Bu deneyim ortamı sonucunda insanların zihninde deneyime dair belirli bir kalite değeri oluşmaktadır. Algılanan kaliteye göre memnuniyet oluşabilmekte veya oluşmayabilmektedir. Memnuniyetler doğrultusunda ise turistlerin deneyim anında veya gelecekteki deneyimlerinde davranış ve tutum değişiklikleri meydana gelmektedir. Meydana gelen bu durumda turistlerin tekrar ziyaret etme ve başkalarına tavsiye etme niyetlerini etkilemektedir (Sharma ve Nayak, 2018).

Literatür taraması sonucunda turistik etkinliklerde unutulmaz yemek deneyimleri yaşanması seyahatin unutulmaz bir anı olarak kalmasında önemli bir faktör olarak görülmektedir. Yaşanılan bu deneyimler de insanların davranışsal niyetlerini olumlu etkilemekte ve ileriki seyahat motivasyonlarında önemli olmaktadır. Bu nedenle seyahatinde unutulmaz yemek deneyimi yaşayan turistler yaşadıkları bu deneyimi başkalarına aktarabilmekte ve destinasyonun imajına pozitif yönlü katkı sağlayabilmektedir.

\section{METODOLOJİ}

Fizyolojik ihtiyaçlardan birisi olan yemek yeme davranışı canlılar için oldukça önemli ve yaşamın devamlılığını sağlamada mecburidir. Bu nedenle bütün canlılar yaşamlarının devamı için beslenmek zorundadır. İnsanlar için de zaruri bir ihtiyaç olan yemek yeme davranışı zamanla zaruri olmanın yanı sıra haz yaşamak ve sosyalleşmek amacıyla yapılan bir faaliyete dönüşmüştür. İnsanlar günlük rutinlerinden kurtulmak ve rahatlamak için çeşitli faaliyetlere katılmaktadır. Yeme-içme faaliyetleri de insanların hoş vakit geçirmek için yaptıkları önemli aktivitelerden birisidir. Günümüzde çok sayıda insan bilmedikleri veya merak ettikleri tatları deneyimlemek için bulundukları destinasyonların dışına çıkmakta veya yaşadıkları bölgedeki restoranlarda yemek deneyimi yaşamaktadır. Yaşanılan bu deneyimleri insanlar hafızalarına kazımakta ve bu deneyimlere bağlı olarak bir davranış geliştirmektedir. Bu nedenle olumlu bir 
şekilde sonuçlanan yemek yeme aktivitesi insanların unutulmaz yemek deneyimi oluşturmalarına katkı sağlamaktadır. Yaşanılan bu deneyim de insanların davranışlarını olumlu yönde etkilemektedir. Yaşanılan unutulmaz yemek deneyimi sayesinde insanlar o bölge veya o bölgede bulunan restoran hakkında bir izlenim oluşturmakta ve oluşturduğu o izlenime göre hareket etmektedir. Bu nedenle insanların yaşadıkları unutulmaz yemek deneyimleri davranışlarına etki etmektedir. Hazırlanan bu çalışma Türkiye'nin gastronomi turizm merkezi olarak bilinen Gaziantep'i ziyaret eden yerli turistlerin unutulmaz turizm deneyimleri ile davranışsal niyetleri arasındaki ilişkiyi belirlemek için hazırlanmıştır. Literatür destekli hazırlanan bu çalışmada aşağıda yer alan modele bağlı olarak belirlenen hipotezler test edilmiştir.

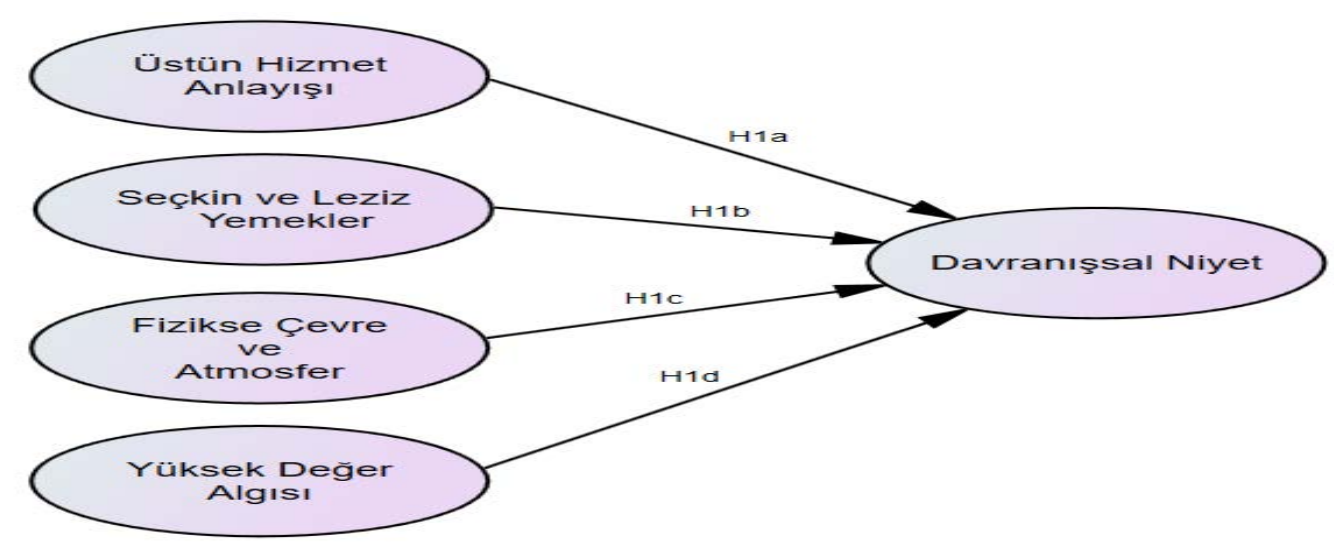

Şekil 1. Araştırma Modeli

H1: Unutulmaz yemek deneyimi ile davranışsal niyet arasında pozitif yönlü ve anlamlı bir ilişki vardir.

H1a: Unutulmaz yemek deneyiminin boyutlarından birisi olan üstün hizmet anlayışı ve davranışsal niyet arasında pozitif yönlü ve anlamlı bir ilişki vardır.

H1b: Seçkin ve leziz yemekler ile davranışsal niyet arasında pozitif yönlü ve anlamlı bir ilişki vardır.

H1c: Fiziksel çevre ve atmosfer ile davranışsal niyet arasında pozitif yönlü ve anlamlı bir ilişki vardır.

H1d: Yüksek değer algısı ile davranışsal niyet arasında pozitif yönlü ve anlamlı bir ilişki vardır.

\section{Veri Toplama Yöntemi}

Hazırlanan bu çalışmada nicel araştırma yönteminden faydalanılmıştır. Analizler için gerekli olan veriler anket tekniğinden faydalanılarak elde edilmiştir. Araştırmada kullanılan anketlerin uygulanabilirliği için Nevşehir Hacı Bektaş Veli Üniversitesinden 23.06.2020 tarihli etik kurul raporu alınmıştır. Araştırma kapsamında, unutulmaz yemek deneyimini ölçmek için Tsaur ve Lo (2020) tarafından geliştirilen 4 boyut ve 17 maddeden oluşan unutulmaz yemek deneyimi (UYD) ölçeğinden, davranışsal niyeti ölçmek için Yang ve Peterson (2004) tarafından geliştirilen, Akkılıç ve Varol (2015) tarafından uygulanan tek boyut ve 6 maddeden oluşan davranışsal niyet (DN) ölçeğinden faydalanılmıştır. Ölçekler çalışma amacına göre dizayn edilmiştir. Kullanılan ölçeklerin yanı sıra Gaziantep'i ziyaret eden ve yeme-içme aktivitelerine katılan yerli turistlere restoranlara yönelik bakış açılarını belirlemek ve dışarı da yemek yeme davranışlarını tespit 
edebilmek için"COVID-19'dan sonra restoran tercihiniz değişecek mi?" ve "Covid-19'dan sonra dışarıda yemek yeme davranışını değişecek mi?" şeklinde iki soru sorulmuştur.

\section{Evren ve Örneklem}

Çalışmanın evrenini Gaziantep'i ziyaret eden ve yeme-içme deneyimi yaşayan yerli turistler oluşturmaktadır. Gastronomi turizmi açısından Türkiye'nin en önemli merkezlerinden biri olması Gaziantep'in evren olarak belirlenmesinde etkili olmuştur. Çalışma esnasında veriler, tesadüfi örnekleme yöntemlerinden birisi olan basit kümeleme örneklem tekniğiyle MayısHaziran 2020 aralığında, bölgeyi ziyaret etmiş turistlere e-anket uygulanarak toplanmıştır. Toplamda 500 kişi ile iletişime geçilmiş, 345 dönüt sağlanmıştır.

\section{ARAŞTIRMA BULGULARI}

Çalışmada ilk olarak verilerin normal dağılıma sahip olup olmadığını belirlemek için "çarpıklık ve basıklık" değerleri incelenmiştir. Tabachnik, Fidell ve Ullman (2007) verilerin çarpıklık ve basıklık değerlerinin $-1,5$ ile 1,5 arasında olması gerektiğini söylemiştir. Ölçek maddeleri incelendiğinde çarpıklık ve basıklık değerlerinin -1,5 ile 1,5 aralığında olduğu ve değişkenlere ait verilerin çoklu normal dağılım gösterdiği tespit edilmiştir. Çarpıklık ve basıklık değerlerinin uygunluğu belirlendikten sonra ölçeklerin geçerlilik ve güvenirliklerine yönelik analizler gerçekleştirilmiştir.

Tablo 1. Verilerin Dağılımı ve Güvenilirliğine İlişkin Bulgular

\begin{tabular}{|c|c|c|c|c|c|c|}
\hline & FaktörYükleri & & & & & \\
\hline Faktörler / Maddeler & AFA/ DFA & Çarpıklık & Basıklık & CA & CR & AVE \\
\hline UYD Faktör: Üstün Hizmet Anlayışı (ÜHA) & & & & 904 & ,926 & 678 \\
\hline $\begin{array}{l}\text { Genel olarak bu bölgede gittiğim restoranlardaki } \\
\text { çalışanları tüm servis ihtiyaçlarımı karşılamak } \\
\text { için ellerinden gelenin en iyisini yapar. }\end{array}$ &, $717 /, 650$ & $-1,08$ & 1,49 & & & \\
\hline $\begin{array}{l}\text { Genel olarak bu bölgede gittiğim restoranlarda } \\
\text { bana çok iyi muamele edilir ve benimle çok iyi bir } \\
\text { şekilde ilgilenilir. }\end{array}$ & ,712/,655 &,- 93 & 1,39 & & & \\
\hline $\begin{array}{l}\text { Genel olarak bu bölgede gittiğim restoranlarda } \\
\text { servis hizmeti profesyonel ve çok kalitelidir. }\end{array}$ & ,780/,766 &,- 92 & 85 & & & \\
\hline $\begin{array}{l}\text { Genel olarak bu bölgede gittiğim restoranlar bana } \\
\text { yüksek hizmet memnuniyeti sağlar. }\end{array}$ & ,791/,886 &,- 86 & 81 & & & \\
\hline $\begin{array}{l}\text { Genel olarak bu bölgede gittiğim restoranlar bana } \\
\text { özenli hizmet sunar. }\end{array}$ & ,794/,882 &,- 87 & ,58 & & & \\
\hline $\begin{array}{l}\text { Genel olarak bu bölgede gittiğim restoranlar } \\
\text { beklentilerimin üzerinde hizmet sağlar. }\end{array}$ & ,716/,810 &,- 63 & 18 & & & \\
\hline UYD Faktör: Seçkin ve Leziz Yemekler (SLY) & & & & 894 & ,905 & ,761 \\
\hline $\begin{array}{l}\text { Genel olarak bu bölgede gittiğim restoranlarm } \\
\text { yemekleri eşsiz bir lezzettedir. }\end{array}$ &, $834 /, 768$ & $-1,08$ & 1,24 & & & \\
\hline $\begin{array}{l}\text { Genel olarak bu bölgede gittiğim restoranlarda } \\
\text { deneyimlediğim tat ve tazelik beklentilerimin } \\
\text { üstündedir. }\end{array}$ &, $828 /, 914$ & $-1,03$ & ,77 & & & \\
\hline $\begin{array}{l}\text { Genel olarak bu bölgede gittiüim restoranlarda } \\
\text { yemekler özenle hazırlanmıştır. }\end{array}$ &, $655 /, 702$ &,- 86 & 89 & & & \\
\hline
\end{tabular}




\begin{tabular}{|c|c|c|c|c|c|c|}
\hline $\begin{array}{l}\text { Genel olarak bu bölgede gittiğim restoranlar bana } \\
\text { unutulmaz tatlar sunmaktadır. }\end{array}$ & ,823/923 & $-1,28$ & 1,46 & & & \\
\hline $\begin{array}{l}\text { UYD Faktör: Fiziksel Çevre ve Atmosfer } \\
\text { (FÇA) }\end{array}$ & & & & 895 & 926 & 758 \\
\hline $\begin{array}{l}\text { Genel olarak bu bölgede gittiğim restoranların iç } \\
\text { dekorasyonu çok etkileyicidir. }\end{array}$ &, $825 /, 831$ &,- 24 &,- 49 & & & \\
\hline $\begin{array}{l}\text { Genel olarak bu bölgede gittiğim restoranların } \\
\text { tarzını çok severim. }\end{array}$ &, $639 /, 807$ &,- 57 &,- 08 & & & \\
\hline $\begin{array}{l}\text { Genel olarak bu bölgede gittiğim restoranlarm } \\
\text { manzarası nefes kesicidir. }\end{array}$ &, $831 /, 781$ & ,35 &,- 46 & & & \\
\hline $\begin{array}{l}\text { Genel olarak bu bölgede gittiğim restoranların } \\
\text { yemek yeme ortamı benzersiz derecede özeldir. }\end{array}$ &, $819 /, 886$ &,- 11 &,- 77 & & & \\
\hline UYD Faktör Yüksek Değer Algısı (YDA) & & & & ,913 & 933 & ,701 \\
\hline $\begin{array}{l}\text { Genel olarak bu bölgede gittiğim restoranlar bana } \\
\text { ekstra hizmet sağlar. }\end{array}$ &, $693 /, 769$ &,- 28 &,- 85 & & & \\
\hline $\begin{array}{l}\text { Genel olarak bu bölgede gittiŭim restoranlar } \\
\text { yemek yeme deneyimime ek bir değer katar. }\end{array}$ & ,771/,794 &,- 95 &, 51 & & & \\
\hline $\begin{array}{l}\text { Genel olarak bu bölgede gittiğim restoranlar } \\
\text { müşteriye önem verir. }\end{array}$ &, $649 /, 862$ & $-1,08$ & 1,39 & & & \\
\hline
\end{tabular}

Toplam Açıklanan Varyans: 74,805

Kaiser-Meyer-Olkin Örneklem Yeterliliği

Ölçüsï: ,932

Bartlett Küresellik Testi: Ki Kare: 4280,659

Serbestlik derecesi:136 p değeri:,000

\begin{tabular}{llcc}
\hline Davranışsal Niyet & & & $, 913,933,701$ \\
\hline $\begin{array}{l}\text { Restoranlar hakkında benden bilgi isteyen } \\
\text { birine, Gaziantep restoranlarını tavsiye } \\
\text { ederim. }\end{array}$ &, $717 /, 550$ &,- 82 & 1,33 \\
\hline $\begin{array}{l}\text { Eğer bu bölgeye tekrar gelirsem, yeniden } \\
\text { Gaziantep'teki restoranlarda yemek yerim. }\end{array}$ &, $750 /, 614$ & $-1,05$ & 1,24 \\
\hline $\begin{array}{l}\text { Gelecekte yemek yemek için Gaziantep'e } \\
\text { tekrar gidebilirim. }\end{array}$ &, $889 /, 867$ & $-1,18$ &, 84 \\
\hline $\begin{array}{l}\text { Çevremdekilere Gaziantep mutfağ ve } \\
\text { restoranları hakkında olumlu şeyler } \\
\text { söylerim. }\end{array}$ &, $842 /, 747$ & $-1,18$ & 1,43 \\
\hline $\begin{array}{l}\text { Yemek yemek için Gaziantep'i tekrar ziyaret } \\
\text { etmeye yönelik güçlü isteğim var. }\end{array}$ &, $894 /, 941$ & $-1,22$ &, 85 \\
\hline $\begin{array}{l}\text { Arkadaşlarım ve ailemi Gaziantep'te yemek } \\
\text { yemeleri konusunda teşvik etmeyi } \\
\text { düşünüyorum. }\end{array}$ &, $912 /, 957$ & $-1,31$ & 1,30 \\
\hline
\end{tabular}

Toplam Açıklanan Varyans: 70,125

Kaiser-Meyer-Olkin Örneklem Yeterliliği Ölçüsü: ,857

Bartlett Küresellik Testi: Ki Kare: 1683,739 Serbestlik derecesi:15 p değeri:,000

Tablo 1'deki bulgular incelendiğinde ölçeklere ait örneklem sayısının analiz yeterliliğini belirlemek için Kaiser-Meyer-Olkin (KMO) testine bakılmış ve KMO değerlerinin (UYD: ,932 DN: 
,857) uygun olduğu belirlenmiştir. Verilerin faktör analizine uygun olup olmadığını belirlemek amacıyla Bartett's Küresellik Testi uygulanmış ve sonuçların anlamlı olduğu (UYD: $X^{2}=4280,659$; $\mathrm{df}=136, \mathrm{p}=, 000, \mathrm{DN}: \mathrm{X}^{2}=1683,739 ; \mathrm{df}=15, \mathrm{p}=, 000$ ) ortaya konulmuştur. Elde edilen sonuçlar dahilinde KMO değerinin 0,60'tan yüksek olması ve Barlett testinin anlamlı çıkması (Büyüköztürk, 2002), verilerinin faktör analizi için uygun olduğunu göstermiştir.

Ölçek maddelerinin faktör yükleri incelendiğinde Maddelerin yer aldıkları faktörlerdeki yük değerlerinin 0,30 ve üzerinde olması uygun bir ölçü olarak kabul edilmektedir (Kline, 1994). Tablo 1 incelendiğinde ölçek faktör yüklerinin uygun olduğu tespit edilmiştir.

Açıklayıcı ve doğrulayıcı faktör analizlerinin ardından ölçeklerin ve geçerlilik güvenirliklerine yönelik analizler yapılmıştır. Ölçeklerin iç tutarlılık güvenirliğini tespit etmek amacıyla Cronbach Alfa (CA) ve birleşik güvenirlik (CR) değerleri incelenmiştir. İlgili ölçeklerin birleşik güvenirlik ve Cronbach Alfa değerlerinin 0,85 üzerinde (CR minimum ,905, CA minimum ,894) ve kabul edilebilir sınırların üstünde olduğu (Hair vd., 2005; Kalaycı, 2009) ayrıca iç tutarlılık güvenirliğinin sağlandığı görülmektedir. Bu durum ölçek yapısının güvenilir olduğunu ortaya koymaktadır. Ayrıca ölçeğin uyum geçerliliğini belirlemek için ortalama açıklanan varyans (AVE) değerleri hesaplanmıştır. AVE değerlerinin CR değerinden düşük ve 0,50'nin üzerinde olması gerekmektedir (Bagozzi ve Yi, 1988). Yapılan analizlerde ölçeklere ait AVE değerlerinin $C R$ değerlerinden düşük ve 0,50'nin üzerinde olduğu tespit edilmiştir. Bulgular doğrultusunda modelde yer alan değişkenlerin uyum geçerliliğinin olduğu belirlenmiştir.

Ölçeklere yönelik geçerlilik ve güvenirliklerin saptanmasının ardından unutulmaz yemek deneyimi ölçeğinin boyutları ile davranışsal niyet arasındaki korelasyon ilişkileri incelenmiştir. Büyüköztürk (2002) korelasyon katsayısının -1 ile +1 arasında bir değer alabileceğini belirtmiştir.

Tablo 2. Ölçeklere İlişkin Korelasyon Katsayıları Standart Sapma ve Ortalama Değerleri

\begin{tabular}{|c|c|c|c|}
\hline Faktör & Davranışsal Niyet & Ort & SS \\
\hline Üstün $\quad$ Hizmet & ,595 & 3,81 & 751 \\
\hline \multicolumn{4}{|l|}{ Anlayışı (ÜHA) } \\
\hline Seçkin ve Leziz & ,741 & 4,07 & 796 \\
\hline \multicolumn{4}{|l|}{ Yemekler (SLY) } \\
\hline Fiziksel Çevre ve & ,518 & 3,10 & 920 \\
\hline \multicolumn{4}{|l|}{ Atmosfer (FÇA) } \\
\hline $\begin{array}{l}\text { Yüksek Değer Algısı } \\
\text { (YDA) }\end{array}$ & 649 & 3,62 & ,914 \\
\hline Davr. Niyet (DN) & - & 4,07 & 826 \\
\hline
\end{tabular}

Tablo 2 incelendiğinde unutulmaz yemek deneyiminin boyutları ile davranışsal niyet arasında pozitif yönlü korelasyon ilişkilerinin olduğu tespit edilmiştir. En yüksek korelasyon ilişkisinin ise seçkin ve leziz yemekler ile davranışsal niyet arasında olduğu belirlenmiştir. 


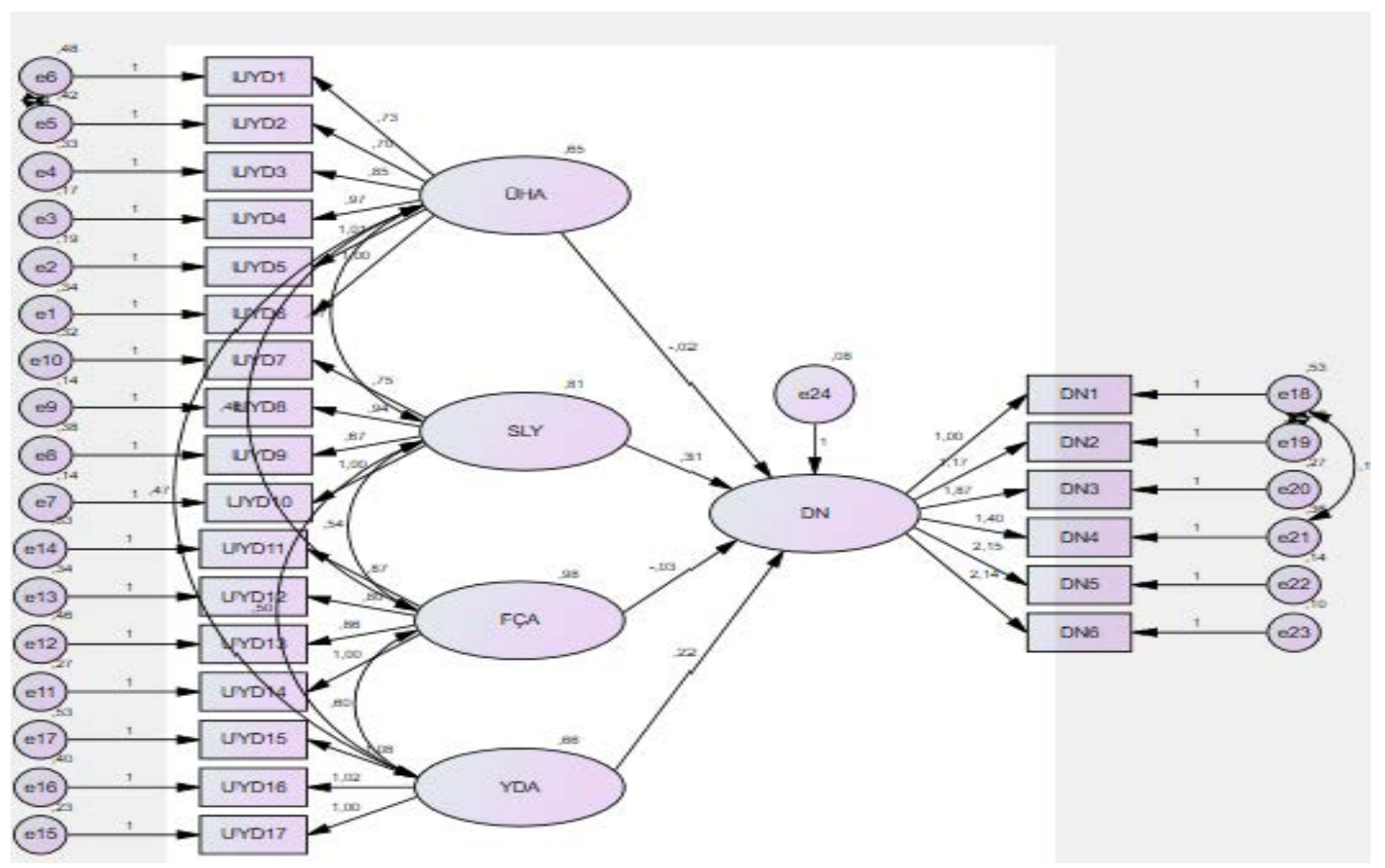

Şekil 2: Model Analizi

\begin{tabular}{ccccc}
\hline$\Delta \chi^{2} / \mathrm{df}$ & RMSEA & CFI & IFI & NFI \\
2,683 &, 070 &, 942 &, 943 &, 911 \\
\hline İlişkiler & B & S.H & P & Hipotezler \\
ÜHA----> DN &,- 028 &, 036 &, 645 & Red \\
SLY-----> DN &, 577 &, 040 & $* * *$ & Kabul \\
FÇA-----> DN &,- 065 &, 032 &, 315 & Red \\
YDA-----> DN &, 376 &, 053 & $* * *$ & Kabul \\
\hline
\end{tabular}

$\mathrm{p}<, 001$

Korelasyon analizlerinden sonra hipotez testlerine yönelik analizlere geçilmiştir. Şekil 2 incelendiğinde modele yönelik uyum iyiliği değerleri görülmektedir ( $\Delta \chi^{2} / \mathrm{df}: 2,683$, RMSEA: ,070, CFI: ,942, IFI: ,943, NFI: ,911). Hair ve arkadaşlarına (2005) göre elde edilen değerlerin kabul edilebilir değer aralığında olduğu söylenebilir.

Hipotezlere yönelik analiz sonuçları incelendiğinde unutulmaz yemek deneyiminin boyutlarından olan SLY ve YDA ile DN arasında pozitif yönlü ve anlamlı ilişkinin olduğu, ÜHA ve FÇA ile DN arasında ise istatistiki olarak anlamlı bir ilişkinin bulunmadığı tespit edilmiştir. Elde edilen bulgular neticesinde H1b ve H1d kabul edilirken, H1a ve H1c reddedilmiştir.

Hipotezlerin testinden sonra covid- 19 pandemisi'nin restoran tercihi ve dişarıda yemek yeme davranışını etkileyip etkilemediği yönünde katılımcılara iki soru sorulmuştur. "Covid-19'dan sonra dışarıda yemek yeme davranışını değişecek mi?" sorusuna katılımciların \%69,9'u evet değişecek yanıtı verirken, \%30,4'ü hayır değişmeyecek şeklinde cevap vermiştir. Elde edilen bu veri çalışmaya katılım gösteren bireylerin dışarıda yemek yeme davranışlarının farklılaşacağını göstermektedir. Bu nedenle yeme-içme işletmeleri covid-19 sonrası müşteri beklentilerinin neler olduğunu iyi tespit etmeli ve bu konuda gerekli düzenlemeleri yapmalıdır. Katılımcılara 
yönlendirilen bir diğer soru ise "Covid-19'dan sonra restoran tercihiniz değişecek mi?" sorusudur. Bu ifadeye katılımcıların \%55,9'u evet değişecek yanıtı verirken $\% 44,1^{\prime} \mathrm{i}$ hayır değişmeyecek şeklinde cevap vermişlerdir. Çalışmaya katılan 345 kişinin yarısından daha fazlasının restoran tercihlerinin değişimine yönelik düşünceye sahip olmaları restoran işletmelerinin covid-19 tedbirleri konusunda hassas olmaları gerekliliğini ortaya koymuştur. Elde edilen bu sonuç Gaziantep'i ziyaret eden yerli turistlerin dışarıda yemek yeme davranışları ve restoran tercihlerinin farklılaşacağını ortaya koymuştur. Elde edilen bu sonuç neticesinde bölge restoranları gerekli düzenlemeleri yaparak hem potansiyel müşterilerini elde tutacak önlemleri almalı hem de müşteri memnuniyetini artırabilecekleri tedbirleri gözden geçirmelidir.

\section{SONUÇ ve ÖNERILER}

Unutulmaz deneyimler, pek çok insanın turistik seyahatlerinde yaşamayı umut ettikleri, somut ve soyut olabilen ve eşsiz güzellikleri kapsayan deneyimlerdir. Destinasyonun tanınmasında önemli bir faktör olan kültürel yiyecek ve içecekler ise unutulmaz deneyimlerin gerçekleştirilmesinde etkin rol oynarlar. Yerel yiyecekler, turistlerin unutulmaz yemek deneyiminde yiyeceklerin doğallığına güven duymaları için önem arz etmektedir. Turistler yerel yiyecekler sayesinde, destinasyonun özgünlügüne güven duymakta ve bu güvenlerini hem başkaları ile paylaşarak hem de tekrar ziyaret davranışlarında bulunarak göstermektedirler (Anton vd. 2019).

Yapılan bu çalışma, Anton vd. (2019)'nin, Chang vd. (2011)' nin ve Tsaur ve Lo (2020)'nun çalışma bulguları ile benzerlik göstermektedir. Çalışmada desteklenen iki hipoteze göre, insanların destinasyonda yaşadıkları turistik aktivitelerde, yemek deneyimlerinde bulunmaları, gerçekleştirilen deneyimin unutulmazlığının sağlanmasında önemli rol oynamaktadır. Aynı zamanda yemeklerin lezzetli ve doğal olması, insanların yemekleri değerli algılamasını sağlamaktadır. Yemeklerin unutulmaz deneyimler gerçekleştirilmesini sağlaması ile turistlerde tekrar ziyaret davranışları oluşmakta ve unutulmaz yemek deneyimlerinin davranışsal niyete yönelik etkisi görülmektedir. Cao vd., (2019)'nin yaptığı çalışmada yemek kalitesi, hizmet kalitesi ve atmosfer unsurlarının, turistlerin yaşadıkları deneyimi kaliteli ve unutulmaz algılamalarında etkin rol oynadığı belirlenmiştir. Packer (2006)' a göre insanların destinasyon alanını ziyaret etme nedenleri arasında eğlence, sosyal temas ve dekorasyon gibi unsurlar etkili olmaktadır. Fakat bu çalışmanın bulgularında, fiziksel çevre ve atmosfer ile yüksek değer algısı ile davranışsal niyetle arasında anlamlı bir ilişki tespit edilememiştir. Çıkan bu sonuca bağlı olarak Gaziantep'te hizmet sunan restoranlar fiziki şartlarını geliştirmeleri ve restoran atmosferlerini tekrar gözden geçirerek yüksek değer algısı meydana getirebilecek fiziki şartlar oluşturmalıdır. Fiziki şartlar iyileştirirken restoran ambiyansı, iç dekorasyon ve kullanılan salon takımlarının iyileştirilmesi atmosferin iyileştirilmesine katkı sağlayabilir.

Stone vd., (2017)' nin yaptığı çalışmaya göre unutulmaz yemek deneyimlerinin gerçekleştirilme sürecinde destinasyon alanını oluşturan tüm unsurlar deneyim anının unutulmaz olmasında etkili olmaktadır. Yiyecek deneyimlerde yiyecekler, restoran, yorumlar, diğer misafirlerle ilişkiler ve hizmet gibi unsurlar, turistlerin deneyim sonrası algıların etkileyerek deneyimlerin unutulmazlığını sağlayabilmektedir. Nitekim, gerçekleştirilen bu çalışmada da yiyeceklerin değer algısı ve yiyeceklerin lezzeti davranışsal niyette etkili olmuştur. Ayrıca Hsu ve Scot (2020)'un yaptığı çalışmada, destinasyon imajı ve ziyaret edilen yerle ilgili duygusal bir bağ oluşturmada yemek deneyiminin etkili bir rolü olduğu ve turistlerin destinasyonu tekrar ziyaret etme niyetini olumlu yönde etkilediği belirlenmiştir. Yapılan bu çalışmada da belirtilen çalışma bulgularına benzer bulgular elde edilmiştir. 
Çalışmadan elde edilen sonuçlar dahilinde Gaziantep'i ziyaret eden turistlerin unutulmaz yemek deneyimi yaşamasında etkili olan en önemli boyutun seçkin ve leziz yemekler boyutu olduğu bunu yüksek değer algısı boyutunun takip ettiği görülmektedir. Elde edilen bu bulgu bölge yemeklerinin oldukça lezzetli algılandığının ve yiyeceklere yüksek oranda değer verildiğinin kanitı olabilir. Bu nedenle Gaziantep sahip olduğu bu gastronomik değerini ve yiyecek lezzet kalitesini korumalı ve sürdürülebilir hale getirmelidir. Sürdürülebilirliğin devam ettirilmesinde eşsiz lezzetlerin standart reçeteleri korunarak sürdürülebilir gastronomi değerleri koruma altına alınabilir. Çünkü lezzetli ve değerli olan bir yemeğin her seferinde aynı keyfi yaşatmasında standartlaşma önemli görülmektedir. Aynı zamanda iyi bir yemeğin iyi fiziksel çevre şartlarında deneyimlenmesi turistlerin unutulmaz anlar yaşamalarına ve olumlu duygular içerisine girmelerine katkı sağlayacaktır. Yaşanılan bu kaliteli yemek deneyimleri de turistlerin gastronomi seyahatlerinde davranışsal niyetlerini olumlu yönde etkileyerek bölgeyi tekrar ziyaret etmelerine ve başkalarına tavsiyede bulunmalarına katkı sağlayacaktır. Bulgulardan elde edilen sonuçlar dahilinde Gaziantep'te yer alan yeme-içme işletme yöneticileri müşterilerine iyi dizayn edilmiş mekanlarda kaliteli yemekler sunduklarında daha fazla kişinin memnuniyetini kazanacaklardır.

Unutulmaz yemek deneyiminin davranışsal niyetle ilişkisi paralelinde, Covid- 19'un etkilerini ölçmek amaciyla elde edilen bulgular Gaziantep'i ziyaret etmiş ve bu bölgede restoran deneyimi yaşamış 345 katılımcı ile sınırlı olmakla birlikte pandemi sonrasında insanların yeme-içme davranışlarını değiştirmeye eğilimli olduklarını göstermesi açısından oldukça önemlidir. İnsanların unutulmaz yemek deneyimleri yaşamalarında yediği yemekler ve aldığı hizmetlerin son derece önemli olduğu yadsınamaz bir gerçek olmasının yanı sıra insanların dışarıda yemek davranışı gerçekleştirmelerinde önemli bir etkiye sahip olan yeme-içme işletmelerinin covid-19 tedbirlerini düzgün şekilde uygulamaları, misafirlerin sağlığını tehlikeye atacak unsurları iyi tespit etmeleri ve önlemeleri, covid-19'un meydana getirdiği psikolojik korkuyu en aza indirecek önlemleri almaları gerekli görülmektedir. Bu nedenle araştırmacılar neofobik davranışların arttığı pandemi döneminde yeme-içme korkusunun azaltılmasına yönelik çalışmalar yaparak işletmelerin bu olumsuzluktan kurtulmalarına ve misafirlerin unutulmaz yemek deneyimi yaşamalarına katkı sağlayabilirler. Ayrıca unutulmaz yemek deneyimlerinin yaşanmasında yemek kalitesi, restoran memnuniyeti, yemek imajı gibi unsurların etkili olup olmadığı tespit edilebilir.

\section{KAYNAKÇA}

Ajzen, I. (1991). The theory of planned behavior. Organizational Behavior and Human, Decision Processes, 50(2), 179-211.

Akkılıç, M.E. ve Varol, İ. (2015). Turist algılarının davranışsal niyetler üzerindeki etkisi: Edremit Körfezi örneği, International Review of Economics and Management, 3(1), 14-38.

Anton, C. Camarero, C. Laguna, M. and Buhalis, D. (2019). Impacts of authenticity, degree of adaptation and cultural contrast on travelers' memorable gastronomy experiences, Journal of Hospitality Marketing \& Management, 28(7), 743-764.

Bagozzi, R. and Yi, Y. (1988). On the evolution of structural equation models, Journal of the Academy of Marketing, 16, 74-94.

Berenguer, J. (2010). The Effect of empathy in environmental moral reasoning. Environment and Behavior, 42(1), 110-134. 
Björk, P. and Kauppinen-Raisanen, H. (2014). Culinary-gastronomic tourism-a search for local food experiences, Nutrition \& Food Science, 44(4), 294-309.

Brown, T. J. Ham, S. H. and Hughes, M. (2010). Picking up litter: an application of theory-based communication to influence tourist behaviour in protected areas, Journal of Sustainable Tourism, 18(7), 879-900.

Büyüköztürk, Ş. (2002). Veri Analizi El Kitabı, Pegem Yayıncılık, Ankara.

Cao, Y. Lib, X. Dipietro, R. and So, K.K.F. (2018). Thecreation ofmemorable dining experiences: formative index construction, International Journal of Hospitality Management, 82, 308-317.

Carŭ, A. and Cova, B. (2003). Revisiting consumption experience, Marketing Theory, 3(2), 267-286.

Chang, R.C., Kivela, J. and Mak, A.H. (2011). Attributes that influence the evaluation of travel dining experience: when East meets West, Tourism Management, 32 (2), 307-316.

Chen, M.F. and Tung, P.J. (2014). Developing an extended theory of planned behavior model to predict consumers' intention to visit green hotels, International Journal of Hospitality Management, $36,221-230$.

Chhabra, D. Lee, W. Zhao, S. and Scott, K. (2013). Marketing of ethnic food experiences: Authentication analysis of Indian cuisine abroad, Journal of Heritage Tourism, 8(2-3), 145-157

Chen, Q. and Huang, R. (2018). Local food in China: a viable destination attraction, British Food Journal, 120(1), 146-157.

Cohen, E. and Avieli, N. (2004). Food in tourism: attraction and impediment, Annals of Tourism Research, 31(4), 755-78.

De Groot, J. I. M. and Steg, L. (2009). Morality and prosocial behavior: The role of awareness, responsibility, and norms in the norm activation model, The Journal of Social Psychology, 149(4), $425-449$.

Dickson, S. and Hall, T. E. (2006). An examination of whitewater boaters' expectations: Are pretrip and post-trip measures consist, Leisure Sciences, 28(1), 1-16.

Ellis, A. Park, E. Kim, S. and Yeoman, I. (2018). What is food tourism, Tourism Management, 68, 250-263.

Fluker, M. R. and Turner, L. W. (2000). Needs, motivations, and expectations of a commercial whitewater rafting experience, Journal of Travel Research, 38(4), 380-389.

Gilmore, J.H. and Pine, B.J. (2007). Authenticity: What Consumers Really Want, Harvard Business School Press, Boston.

Gonzălez Santa Cruz, F. Choque Tito, J. Pĕrez-Gălvez, J. C. and Medina-Viruel, M. J. (2019). Gastronomic experiences of foreign tourists in developing countries. The case in the city of Oruro (Bolivia), Heliyon, 5(7), 1-8.

Gordin, V. and Trabskaya, J. (2013). The role of gastronomic brands in tourist destination promotion: the case of St. Petersburg, Place Branding Public Diplomacy, 9 (3), 189-201.

Hair, F. Jr. Black, W. C. Babin, B. J. Anderson, R. E. and Tatham, R. L. (2005). Multivariate data analysis, (6th ed.), New Jersey: Prentice Hall.

Hsu, F. C., and Scott, N. (2020). Food experience, place attachment, destination image and the role of food-related personality traits, Journal of Hospitality and Tourism Management, 44, 79-87. 
Han, H. Jae, M. and Hwang, J. (2016). Cruise travelers' environmentally responsible decisionmaking: An integrative framework of goal-directed behavior and norm activation process, International Journal of Hospitality Management, 53, 94-105.

Haven-Tang, C. and Jones, E. (2005). Using local food and drink to differentiate tourism destinations through a sense of place: a story from Wales-Dining at Mommouthshires Great Table, Journal of Culinary Science and Technology, 4(4), 69-86.

Henderson, J.C. (2009). Food tourism reviewed, British Food Journal, 111(4), 317-326.

Hjalager, A. M. and Corigliano, M. A. (2000). Food for tourists' determinants of an image, International Journal of Tourism Research, 2, 281-293.

Huang, J. (2017). The dining experience of Beijing Roast Duck: A comparative study of the Chinese and English online consumer reviews, International Journal of Hospitality Management, 66, 117-129.

Ignatov, E. and Smith, S. (2006). Segmenting Canadian culinary tourists, Current Issues in Tourism, 9(3), 235-255.

Kalaycı, Ş. (2009). Spss uygulamalı çok değgişkenli istatistik teknikleri, Asil Yayın Dağıtım, Ankara.

Keskin, E. Sezen, N. ve Dağ, T. (2020). Unutulmaz turizm deneyimi, müşteri memnuniyeti, tekrar ziyaret ve tavsiye etme niyeti arasındaki ilişkiler: Kapadokya bölgesini ziyaret eden turistlere yönelik bir araştırma, Journal of Recreation and Tourism Research, 7(2), 239-264.

Keskin, E., Solunoğlu, A. ve Aktaş, F. (2020). Yiyecek içecek işletmelerinde memnuniyetin tekrar ziyaret niyeti üzerindeki etkisinde atmosfer ve sadakatin aracı ve düzenleyici rolü; Kapadokya Örneği, Journal of Tourism and Gastronomy Studies, 8(2), 1222-1246.

Kim, J.H. Ritchie, J.R.B. and Mccormick, B. (2012). Development of a Scale to Measure Memorable Tourism Experiences, Journal of Travel Research, 51(1), 12-25.

Kivela, J. J. and Crotts, J. C. (2009). Understanding Travelers' Experiences of Gastronomy Through Etymology and Narration, Journal of Hospitality \& Tourism Research, 33(2), 161-192.

Kline, P. (1994), An easy guide to factor analysis, New York: Routledge.

Kumar, G. M. K. (2019). Gastronomic tourism a way of supplementing tourism in the Andaman \& Nicobar Islands, International Journal of Gastronomy and Food Science, 16, 100139.

Le, T. H. Arcordia, C. Novais, M. A. and Kralj, A. (2019). What we know and do not know about authenticity in dining experiences: A systematic literature review, Tourism Management, 74, 258275.

Liu, J. An, K. and Jang, S. (2020). A model of tourists' civilized behaviors: Toward sustainable coastal tourism in China, Journal of Destination Marketing \& Management, 16, -1-10.

Long, L.M. (2006). Food pilgrimages: seeking the sacred and the authentic in food, Appetite, 47 (3), 393.

Lopez-Guzman, T. Uribe Lotero, C. P. Perez- Galvez, J. C. and Rios Rivera, I. (2017). Gastronomic festivals: attitude, motivation and satisfaction of the tourist. British Food Journal, 119(2), 267-283.

Mak, A. H. N. Lumbers, M. Eves, A. and Chang, R. C. Y. (2012). Factors influencing tourist food consumption, International Journal of Hospitality Management, 31(3), 928-936.

Miao, L. Lehto, X. and Wei W. (2014) The hedonic value of hospitality consumption: Evidence from spring break experiences, Journal of Hospitality Marketing \& Management, 23(2), 99-121. 
Mitchell, R. and Hall, M.C. (2003). Consuming tourist: Food tourism consumer behaviour, food tourism around the world: Development, management and markets, (Editor) M.C. Hall, M.C., Sharples, L., Mitchell, R., Macionis, N. and Cambourne, B. In: Food Tourism Around the Word (ss. 1-24) Oxford and Burlington: Butterworth-Heinemann.

Mykletun, R.J. and Gyimŏthy, S. (2010). Beyond the renaissance of the traditional Voss sheep'shead meal: tradition, culinary art, scariness and entrepreneurship, Tourism Management. 31 (3), 434-446.

Ng, S.I. Lee, J.A. and Soutar, G.N. (2007). Tourists' intention to visit a country: the impact of cultural distance, Tourism Management, 28 (6), 1497-1506.

Ottenbacher, M.C. and Harrington, R.J. (2013). A case study of a culinary tourism campaign in Germany: implications for strategy making and successful implementation, Journal of Hospitality Tourism Research, 37 (1), 3-28.

Packer, J. (2006). Learning for fun: The unique contribution of educational leisure experiences curator, The Museum Journal, 49(3), 329-344.

Pillsbury, R. (1990). From boarding house to bistro, Unwin Hyman, Cambridge.

Pine, J.B. and Gilmore, J.H. (1999). The experience economy, Boston, Harvard Business School Press.

Reynolds, P. (1994). Culinary heritage in the face of tourism. Progress in Tourism, Recreation and Hospitality Management, 6, 189-194.

Richards, G. (2002). Gastronomy: An essential ingredient in tourism production and consumption?, (Editor) Hjalager, A.M. and Richards, G. In: Tourism and Gastronomy (ss.3-21) Routledge: London.

Ritchie, J.R.B. Tung, V.W.S. and Ritchie, R.J.B. (2011). Tourism experience management research: emergence, evolution and future directions, International Journal of Contemporary Hospitality Management, 23(4), 419-438.

Schwartz, S. H. (1977). Normative Influences on Altruism, Advances in Experimental Social Psychology, 10, 221-279.

Sharma, P. and Nayak, J.K. (2018). Testing the role of tourists' emotional experiences in predicting destination image, satisfaction, and behavioral intentions: A case of wellness tourism, Tourism Management Perspectives, 28, 41-52.

Sims, R. (2009). Food, place and authenticity: local food and the sustainable tourism experience, Journal of Sustainable Tourism, 17 (3), 321-336.

Smith, S. (1983). Restaurants and dining out. Geography of a Tourism Business, Annals of Tourism Research, 10, 515-549.

Solunoğlu, A. (2019). Regional impacts of the quality of gastronomic experience, (Editor) Krystev, V., Efe, R. and Atasoy, E. In: Theory and Practice in Social Sciences (ss. 479-487), St. Kliment Ohridski University Press, Sofia.

Song, H. You, G.-J. Reisinger, Y. Lee, C.-K. and Lee, S.-K. (2014). Behavioral intention of visitors to an Oriental medicine festival: An extended model of goal directed behavior, Tourism Management, 42, 101-113.

Su, C. S. (2013). An importance-performance analysis of dining attributes: A comparison of individual and packaged tourists in Taiwan, Asia Pacific Journal of Tourism Research, 18 (6), 573597. 
Şengül, S. (2017). Türkiye'nin gastronomi turizmi destinasyonlarının belirlenmesi: Yerli turistler üzerine bir araştırma, Balıkesir Üniversitesi Sosyal Bilimler Enstitüsü Dergisi, 20(37), 375-396.

Tabachnick, B. G. Fidell, L. S. and Ullman, J. B. (2007). Using Multivariate Statistics, 5. Bask1, Boston: MA, Pearson.

Tsaur, S-H. and Lo, P-C (2020). Measuring memorable dining experiences and related emotions in fine dining restaurants, Journal of Hospitality Marketing and Management. 1-24.

Qu, H., Kim, L. H., and Im, H. H. (2011). A model of destination branding: Integrating the concepts of the branding and destination image, Tourism Management, 32(3), 465-476.

Quan, S. and Wang, N. (2004). Towards a structural model of the tourist experience: an illustration from food experiences in tourism, Tourism Management, 25(3), 297-305.

Yayla, Ö. ve Yaylı, A. (2019). Turistik destinasyonlarda rekreasyonel etkinliklerin hizmet kalitesi ölçümü: Kavramsal bir inceleme, Journal of Tourism and Gastronomy Studies, 7(1), 676-687.

Yaylı, A ve Çetiner, H. (2020). Animasyon aktivitelerinde deneyim kaltesinin otel işletmelerinin imajı, konukların değer algısı ve tekrar satın alma niyetine etkisi, İşletme Araştırmaları Dergisi, 12(1), 749-768.

Yuan, Y.H. (2009). The nature of experience in hospitality settings. Doctoral Theses, Texas: Texas Tech University.

Wijaya, S. King, B. Nguyen, T.-H. and Morrison, A. (2013). International visitor dining experiences: A conceptual framework, Journal of Hospitality and Tourism Management, 20, 34-42. 